\title{
Aging Properties of Polyvinylidenefluoride-Coated Polyesters Used in Tensioned Membrane Structure: Effect of Loading Protocol and Environment
}

\author{
Yingying Zhang ${ }^{1}$ and Mingyue Zhang ${ }^{2}$ \\ ${ }^{1}$ State Key Laboratory for Geomechanics and Deep Underground Engineering, School of Mechanics and Civil Engineering, \\ China University of Mining and Technology, Xuzhou 221116, China \\ ${ }^{2}$ School of Mechanics and Civil Engineering, China University of Mining and Technology, Xuzhou 221116, China \\ Correspondence should be addressed to Yingying Zhang; zhangyingying85@163.com
}

Received 5 March 2017; Accepted 12 April 2017; Published 17 May 2017

Academic Editor: Kohji Tashiro

Copyright @ 2017 Yingying Zhang and Mingyue Zhang. This is an open access article distributed under the Creative Commons Attribution License, which permits unrestricted use, distribution, and reproduction in any medium, provided the original work is properly cited.

\begin{abstract}
This paper presents the degradation behaviors of polyvinylidenefluoride- (PVDF-) coated polyesters used in tensioned membrane structure by artificial accelerated tests, in which the effects of environment factors and loading conditions are studied. Results show that the degradation ratio of main mechanical parameters (tensile strength, tear strength, and elastic modulus) is related to the aging depth of substrate and coating. The degradation of weather resistance can be considered as the accumulation of environment and loads. The ultraviolet radiation and the temperature mainly affect the mechanical properties of yarns, while the preloading before aging tests can change the crimp degrees and decrease the coating thickness. The effect of loads should not be ignored in the weather resistance analysis of PVDF-coated polyesters. A simplified method composed of cyclic tests and stress-relaxation tests is suggested to study the long-term weather resistance of PVDF-coated polyesters. It can provide a theoretical reference for the proposal of resistance partial factor in the design of tensioned membrane structure.
\end{abstract}

\section{Introduction}

As a roof material, the membrane surfaces are usually directly exposed to natural environments. The outer appearance of membrane materials changes and the material strength gradually decreases under natural environments, such as solar, temperature, rain erosion and dust. Meanwhile, as main structural components, the membrane materials suffer from the prestress, wind, snow, and other loads. The weather resistance of membrane materials is strongly related to the safety and durability of the membrane structures [1-3].

The strength of membrane structures depends on the service life, manufacture process, fatigue, temperature, and other environments. Nearly all the factors are related to the scale of membrane structures and the design life cycle [47]. Compared with other conventional materials, there is lack of enough studies on the aging properties of coated fabrics in civil engineering and most of them are in the textile industries and chemical industries [7-9]. However, the related research advances can be references for studying the weatherability of PVDF-coated polyesters used in tensioned membrane structures, due to similar material structures.

There are three main methods to evaluate the aging properties of coated fabrics, including natural exposure test, field aging test, and artificial accelerated test. The natural exposure test is a very effective method, because the test condition is very close to natural environment. Polfus [10] carried out the natural exposure tests of PVC-coated polyesters in different areas and found that the material failure is related to natural environments and the industrial pollution plays an important role in material aging in the industrial zones of east and west coasts of US. Eichert [11] also proposed that the air pollution is an important reason for the aging of membrane materials through a ten-year natural exposure test. Toyada et al. found that the material residual strength is only $50 \%$ of the initial tensile strength after a three-year natural exposure 
test, and it remained almost unchanged in the next four years $[12,13]$. Levinson et al. found that the fouling caused by soot, dust, and biomass accumulation can lead to the decrease of the weatherability of PVC-coated polyesters [14]. Razak et al. [15] carried out the two-year outdoor exposure tests on PVC-coated polyesters and PTFE coated glass fibers in the tropical climate. The $\mathrm{TiO}_{2}$ surface processing technology can improve the weather resistance of PVC-coated polyesters. The thermal-humid environment is more suitable for the growth of the fungal on the surface of PVC coating. The degradations of material surface are more serious in the thermal environment than those in other environments.

The field aging test is to get the test samples from real engineering. It can accurately reflect the material aging in real engineering. However, the sampling of the test specimens is very difficult and the test cycle is too long in real engineering. Therefore, there are few published references on the field aging tests. Zerdzicki et al. [16] carried out the laboratory tests on the 20-year-old PVC fabric of the Sopot Forest Opera roof and used the Bodner-Partom constitutive equations for modelling the technical fabric Valmex used for the hanging roof of the Forest Opera in Sopot in Poland.

Compared with other methods, the artificial accelerated test can significantly shorten the test time and simulate the effects of various environments easily. Generally, due to well controllability and reproducibility, the artificial accelerated aging tests have been widely used by the researchers, especially for the parametric analysis. Ansell [17] carried out a series of aging tests on PVC-coated polyesters and found that the tensile strength decreased, but the elastic modulus increased. The surface darkened gradually and the internal structures changed through the DSC analysis. Mailler et al. [18] presented the biaxial creep curves of high tenacity plain weave polyester (ref. ENKA 174 S) coated with PVC after the artificial accelerated tests and found that the tensile strength decreased about $50 \%$ in the first three years and changed a little in the next four years. Liu et al. [19] got the relationship between radiation time and intensity and the tensile strength and strain at break regarding PVC-coated polyesters. Qiu et al. [20] found that the photooxidation aging mainly appeared in the surface coating of PVC-coated polyesters and the reaction rate under different radiation intensities was out of proportion to the UV intensity. The Schwarzschild law can be used to get the relationship between the mechanical indexes and aging time and radiation intensity [21, 22]. Tan [23] found that the surface of PVC-coated polyesters damaged seriously under the thermal environment, while no significant change was observed on the surface after the ultraviolet radiation. With temperature increasing, the loss of material properties increased and the damage became more serious under the thermal or thermal-humid environment.

As for polymer composites, the physical and chemical performances of building coated fabrics are affected by environment and loading conditions. The effect of loading on the yarns is plastic deformation accumulation of fabrics, yarn slippage, and yarn rupture, which is different from the effect of environment factors $[24,25]$. The mechanical properties of coated fabrics depend on the properties of the substrate, coating formulation, coating technique, and processing conditions during coating [25]. During the loading process, the microstructure changes all the time and the crimps decrease due to the manufacture process. Then, some unrecoverable deformations appear and they affect the material tensile stiffness [26]. Generally, the effects of loading on the aging properties are mainly related to three factors, including stress level, loading time, and environmental factors [2]. The loading condition may affect the aging process and shorten the service life. However, the current studies are mainly concentrated on the variations of mechanical properties due to environment factors, in which the effect of loading conditions is always ignored. Therefore, it is necessary to study the aging properties of coated fabrics under the interaction of loading and environment.

This paper presents the weather resistance of PVDFcoated polyesters by the artificial accelerated tests, including uniaxial tensile behaviors, tear strength, uniaxial elastic modulus, cyclic behaviors, and stress relaxations. The interaction mechanisms of environment factors and loading conditions are studied, in which the cyclic tensile tests and the stressrelaxation tests are used to simulate the stress states in actual engineering. The results can be references for the design and reliability analysis of membrane structure.

\section{Materials and Methodology}

The PVDF-coated polyester (Ferrari 1202T2) produced by Ferrari Company [27] is taken as research object. It is with the thickness of $0.78 \mathrm{~mm}$ and the weight of $1050 \mathrm{~g} / \mathrm{m}^{2}$. Its woven density is $1100 / 1670$ Dtex PES HT in warp and weft, respectively. It is with good pollution resistance and can be used for permanent structures. The Précontraint ${ }^{@}$ technology is used to obtain more consistent and more balanced warp and weft stiffness through the cloth by applying tension to warp and weft of a plain woven fabric [28-30]. Besides, it should be noticed that two types of Précontraint ${ }^{@} 1202$ (S2 and Fluotop T2) are produced. The difference between these fabrics is surface treatment on top (PVDF for S2 or high concentration PVDF for T2). Basic mechanical parameters for both fabrics specified by manufactures are identical [28, 29].

The artificial accelerating tests are conducted by the Xenon Lamp SN-300. According to the inspection specifications of membrane structures, the environment parameters of Xenon Lamp are defined as follows $[31,32]$. The irradiation intensity is $872 \mathrm{~W} / \mathrm{m}^{2}$, the temperature is $63^{\circ} \mathrm{C}$, the relative humidity is $50 \%$, and the rain/dry cycle is $18 \mathrm{~min} / 102 \mathrm{~min}$ (rain/dry). The aging times are 86, 172, 258, 344, 516, and 688 hours, respectively. The corresponding total irradiance is $270,560,810,1080,1620$, and $2160 \mathrm{MJ} / \mathrm{m}^{2}$, respectively. The tensile tests are carried out with the electronic universal tensile machine, immediately after the aging tests. Besides, the wave jigs are used in the tests. In order to avoid the failure near the jigs, the linen canvas is used for protecting the material. If the failure position of samples was very close to the jigs, the test data was invalid and the samples should be discarded. The stress is calculated by the loads recorded 


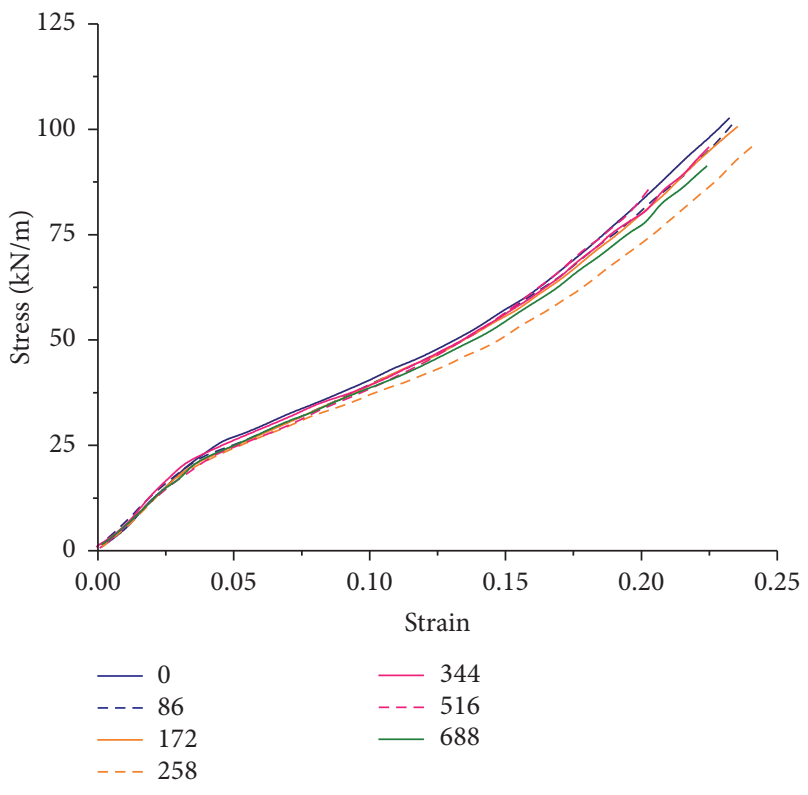

(a) Warp

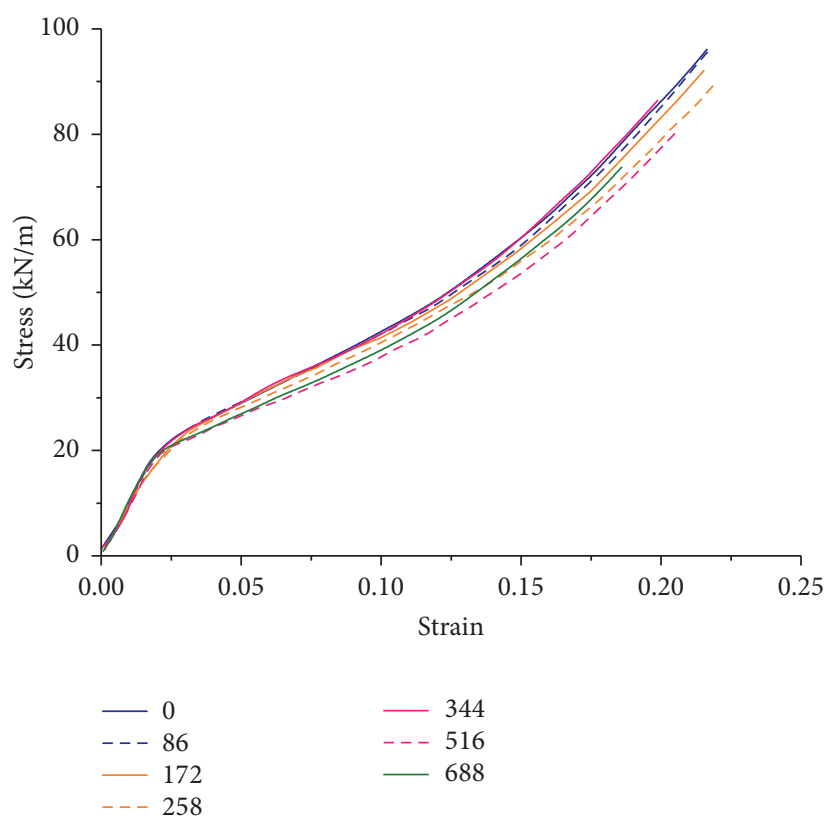

(b) Weft

FIGURE 1: Stress-strain curves of Ferrari 1202 T2 under different aging times.

by the test machine, while the strain is calculated by the displacement of jigs. For each test, at least ten specimens are tested for each group.

The tests can be divided into two parts: the first part is the aging properties without any preloading and the second part is the aging properties of materials preloaded by stressrelaxation or cyclic loading tests.

In the first part, the tensile strength, strain at break, elastic modulus, stress-relaxation behaviors, and cyclic loading behaviors are studied regarding the aging materials without preloading. The test protocols are defined according to DG/TJ 08-2019-2007. (1) The tensile strength and strain at break can be obtained by the uniaxial tensile tests with the tensile rate of $100 \mathrm{~mm} / \mathrm{min}$. The specimens are with the length of $300 \mathrm{~mm}$, the width of $200 \mathrm{~mm}$, and the gauge length $200 \mathrm{~mm}$.

(2) The tear strength is obtained by the method of trapezoidal specimen with the tensile rate of $100 \mathrm{~mm} / \mathrm{min}$. The specimen is with the length of $180 \mathrm{~mm}$, the width of $50 \mathrm{~mm}$, and a $25 \mathrm{~mm}$ slit in the middle of the specimen [33]. (3) The uniaxial elastic modulus is taken as the research object due to small machine volume. The uniaxial elastic modulus can be got by the cyclic tests as follows. The material is first tensioned to the $1 / 4$ of the tensile strength with the tensile rate of $20 \mathrm{~N} / \mathrm{s}$ and then decreases to 0 . After five cycles, the secant slope of the fifth loading curve is taken as the uniaxial elastic modulus $[34,35]$. (4) The stress-relaxation tests and cyclic tensile tests are carried out for the materials after aging, respectively. First, the specimens are put in the Xenon Lamp Box to conduct the artificial accelerated tests with the aging time of 86 hours and 172 hours, respectively. Then, the stress-relaxation tests or cyclic loading tests are carried out on the aging materials. Finally, the specimens are tensioned to fracture and the stressstrain curves are recorded. The initial stress in the stressrelaxation test is $12 \mathrm{kN} / \mathrm{m}$, which lies in the possible service stress range $(3-25 \mathrm{kN} / \mathrm{m})$ in actual engineering. In the cyclic loading tests, the stress amplitude is $3-16 \mathrm{kN} / \mathrm{m}$ and the tensile rate is $20 \mathrm{~N} / \mathrm{s}$.

In the second part, the aging properties of materials preloaded by stress-relaxation and cyclic loading tests are studied. First, the stress-relaxation tests or the cyclic loading tests are carried out on the new materials without initial loading. Then, the specimens are put in the Xenon Lamp Box to conduct the artificial accelerated tests, in which the aging time is 86 hours and 172 hours. Finally, the specimens are tensioned to fracture with the tensile rate of $100 \mathrm{~mm} / \mathrm{min}$.

\section{Results and Discussions}

\subsection{Mechanical Properties of PVDF-Coated \\ Polyesters after Aging}

3.1.1. Basic Mechanical Parameters. In appearance, the material color is yellow, while stains and spots can be observed on the surface after aging. With aging time increasing, significant changes can be observed on the surface, but the trends of stress-strain curves remain almost unchanged, as shown in Figure 1, where the material with the aging time of $0 \mathrm{~h}$ is the reference materials without aging. This is because the coating exposed in the air can absorb the ultraviolet ray in sunshine, especially the wavelength of $290-400 \mathrm{~nm}$. It can lead to the rupture of chemical bonds in the coating and the existing of oxygen can cause the automatic oxidation reaction. The polyesters can absorb the ultraviolet ray with the wavelength of $360 \mathrm{~nm}$. When the wavelength is less than $320 \mathrm{~nm}$, the absorption ratio increased significantly and it can accelerate the aging of the substrate $[36,37]$.

The tensile strength and strain at break of Ferrari 1202 T2 after different aging times are shown in Figure 2. With aging 


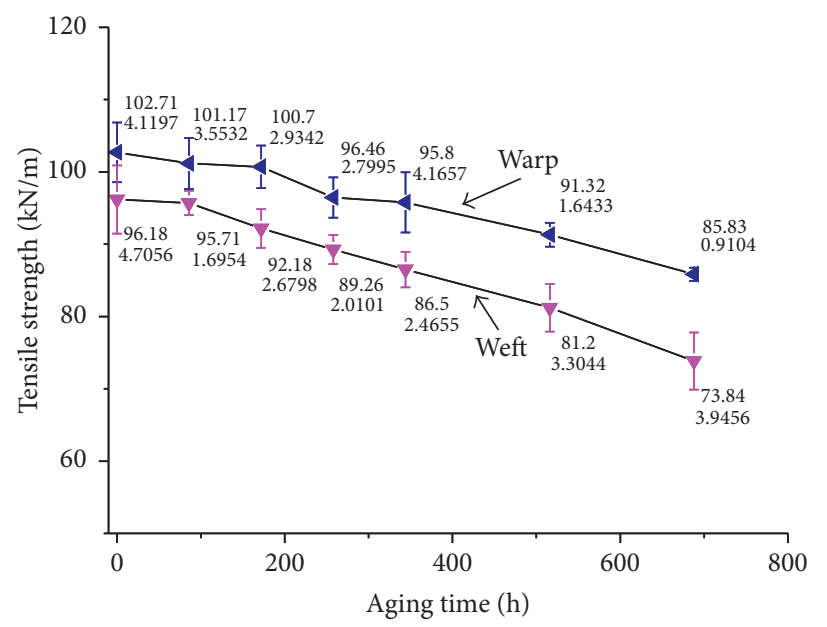

(a) Tensile strength

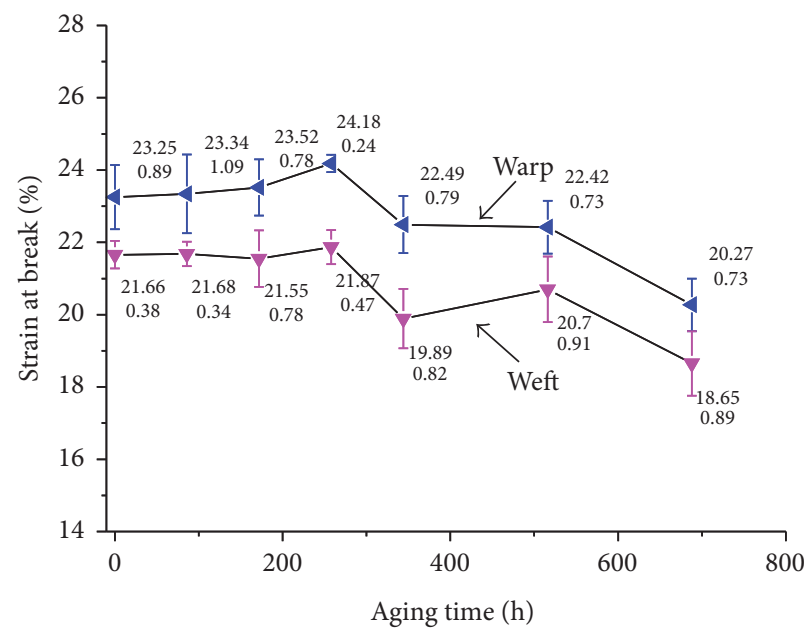

(b) Strain at break

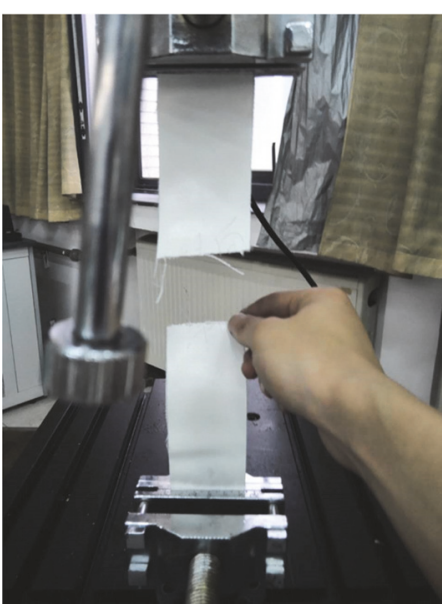

(c) Failure modes

FIGURE 2: Tensile strength and strain at break after different aging times.

time increasing, the tensile strength decreases significantly, which is mainly related to aging degree of coating and substrate. After 86 hours of aging, the degradation ratio of tensile strength is only $1.5 \%$. With aging time increasing, the degradation ratio increases fast and the degradation ratio of tensile strength can achieve $23.3 \%$ after 688 hours of aging. This is consistent with Toyada et al.s research $[12,13]$. With aging time increasing, the decrease rate of warp strength is higher than that of weft strength. The variation trends of strain at break are not significant, because the strain at break is mainly related to failure modes. For failure modes, most of the warp specimens is "yarns even fracture," while most of the weft is "yarn pulled-out." Besides, the accumulative damage failure modes can also be observed in some tests [38].

The variations of tear strength and elastic modulus are shown in Figure 3. It can be seen that the tear strength in weft is higher than that in warp. With aging time increasing, the tear strength decreases gradually and the decrease rate first increases and then decreases. After 688 hours of aging, the degradation ratio of the tear strength is about $25.44 \%$ and $27.99 \%$, respectively, in warp and weft. Besides, the degradation ratio in weft is higher than that in warp. With aging time increasing, the uniaxial elastic modulus decreases gradually. After 688 hours, the uniaxial elastic modulus decreases about $8.81 \%$ and $11.97 \%$, respectively, in warp and weft. It should be noticed that the degradation ratio of uniaxial elastic modulus is far lower than that of the tensile strength and tear strength. This is because that the tensile strength/tear strength mainly depends on failure modes and properties of substrate and coating, while the elastic modulus mainly depends on woven methods and yarn properties [25].

The nonlinear tensile behaviors of coated fabrics are mainly related to the microstructure, including woven method, wave height, and other parameters [25]. The ultraviolet radiations can lead to the degradation of basic material properties, including tensile strength, tear strength, and tensile stiffness. In the beginning, the ultraviolet radiation only leads to the aging of the coating which can protect the substrate, and then the material strength decreases slowly. After the coating is aged in some region and then the ultraviolet radiation will penetrate and affect the substrate directly. Then, the properties of yarns begin to decrease; therefore, the tensile 


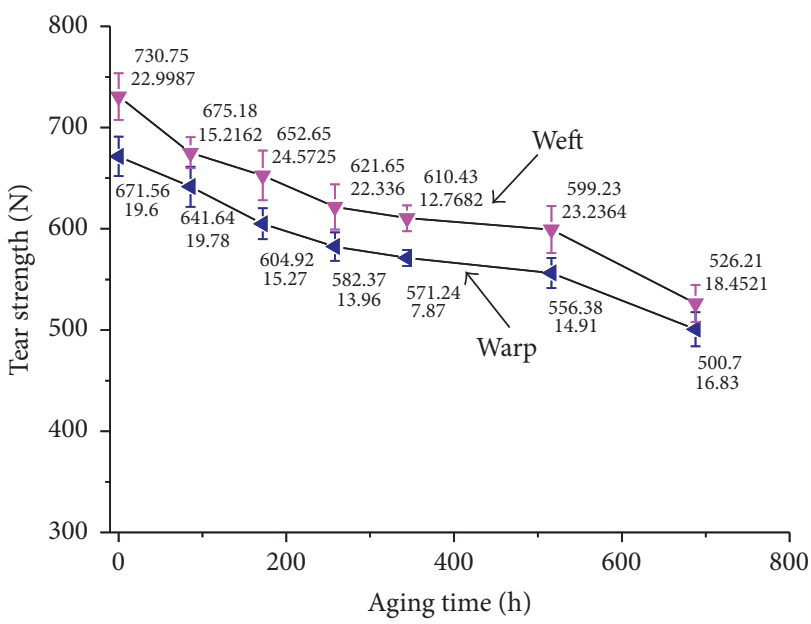

(a) Tear strength

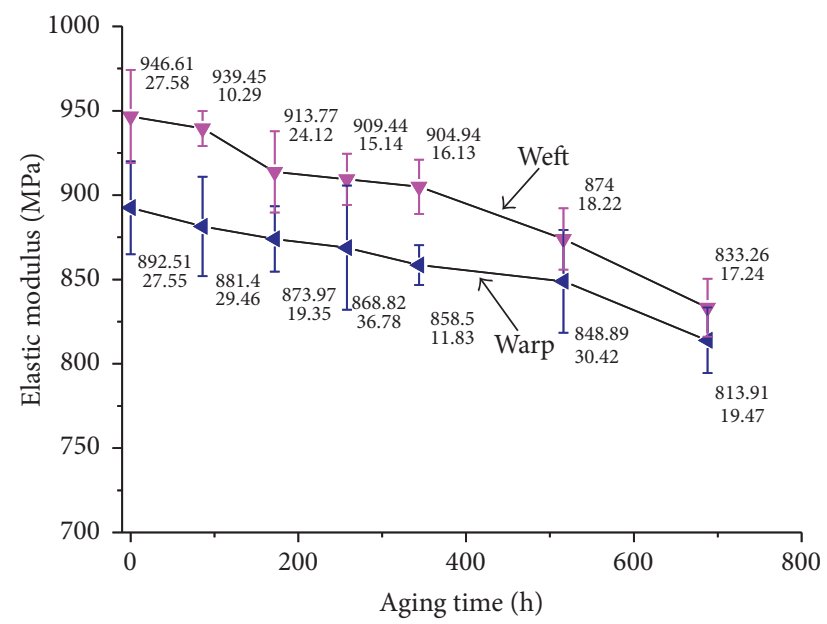

(b) Elastic modulus

FIGURE 3: Tear strength and elastic modulus after different aging times.

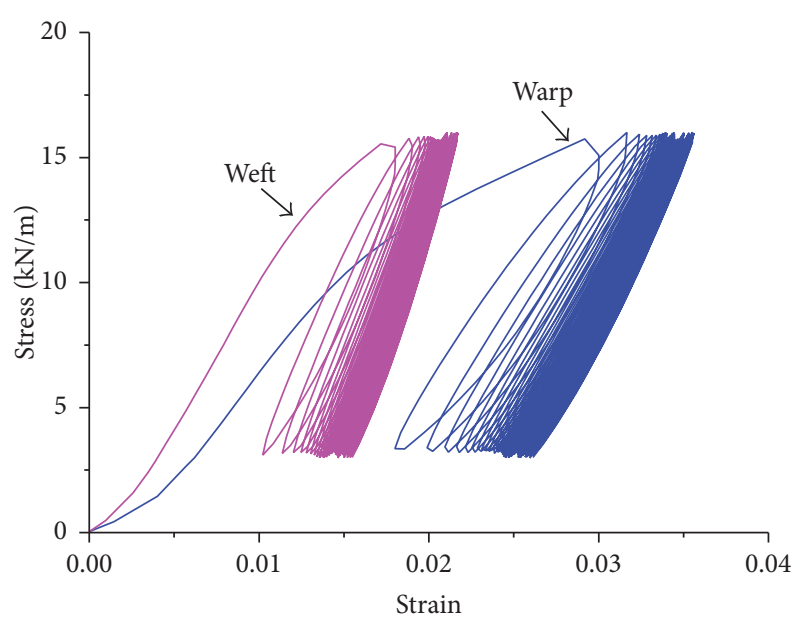

FIgUre 4: Cyclic tensile curves with the stress amplitude of $3-16 \mathrm{kN} / \mathrm{m}$.

strength and the tensile stiffness decrease quickly. Besides, from the stress-relaxation tests in previous references, the tensile stiffness decreases with temperature increasing [28]. From the above, the environment factors, including ultraviolet radiation and temperature, mainly affect the mechanical properties of yarns and coatings. The aging mechanism of substrate yarns is related to yarn types.

\subsubsection{Cyclic Tensile Behaviors and Stress-Relaxation Behaviors.}

The cyclic tensile behaviors with the stress amplitude of $3-16 \mathrm{kN} / \mathrm{m}$ are shown in Figure 4. It is evident that the residual strain after the first cycle is the highest, and the increment of residual strain decreases with cycle number increasing. Finally, the total residual strain tends to a constant. It can be seen that the loading and unloading curves constitute the nonlinear hysteresis loop. The shapes of tensile curves in warp and weft are slightly different. In the same stress level, the weft strain is relatively higher than the warp, while the area of hysteresis cycle in weft is larger than that in the warp. In the unloading curves, due to the viscoelasticity of materials, the relationships between residual strain and cycle number of the materials after different aging times are shown in Figure 5. The residual strain decreases with aging time increasing.

The stress-relaxation behavior is mainly related to the initial stress level and temperature [26]. With initial stress increasing, the degradation ratio of stress relaxation increases, and the decrease rate decreases with time increasing. The stress-relaxation curves of PVC-coated polyesters after aging are shown in Figure 6. In the initial $30 \mathrm{~min}$, the residual stress decreases significantly and the stress degradation decreases gradually with time increasing. With time increasing, the attenuation rate decreases and the remaining stress is stable after $48 \mathrm{~h}$. The remaining stress after $24 \mathrm{~h}$ is only $60 \%$ of the initial stress. The aged materials still performed typically viscoelastic under different aging times. With aging time increasing, the final stable stress and the initial relaxation modulus increase. After $86,172,258,344$, and 516 hours of aging, the final stable stress in warp increases about $2.30 \%, 8.11 \%, 10.30 \%, 14.24 \%$, and $24.87 \%$, respectively, compared with the reference materials $(0 \mathrm{~h})$. Meanwhile, the final stable stress in weft increases about $3.51 \%, 10.14 \%, 17.32 \%$, $24.61 \%$, and $34.06 \%$, respectively. The material hardening phenomenon in weft is slightly significant than that in warp. The differences between the warp and weft are not obvious, compared with those planar woven materials [28].

\subsection{Weather Resistance of PVDF-Coated Polyesters after Preloading}

3.2.1. Cyclic Loading. The artificial accelerated aging tests are carried out on the materials after cyclic loading. The tensile curves of aging materials with and without cyclic loading are shown in Figure 7. It can be seen that, in the first phase, the tensile curves of materials after different aging times are almost the same. In the second phase, the yarns and coatings 


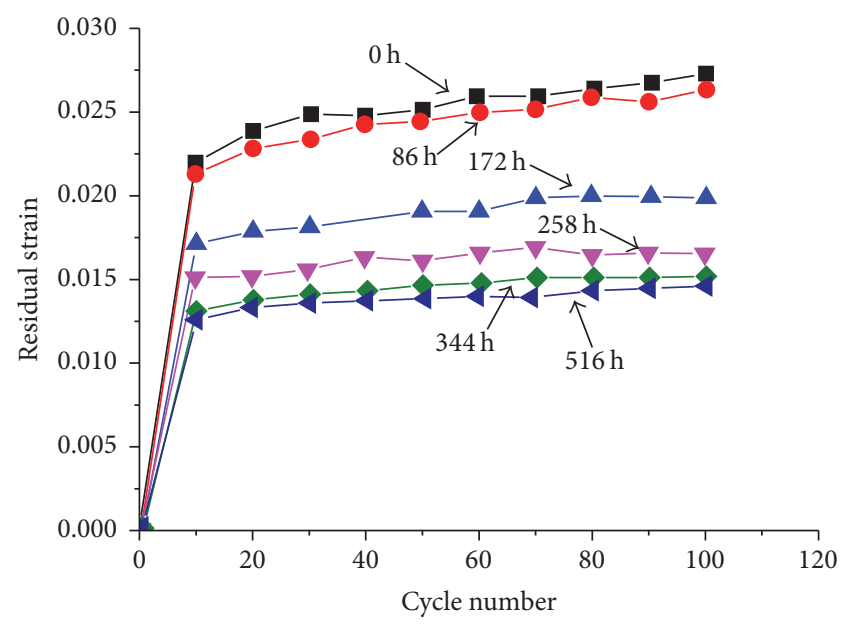

(a) Warp

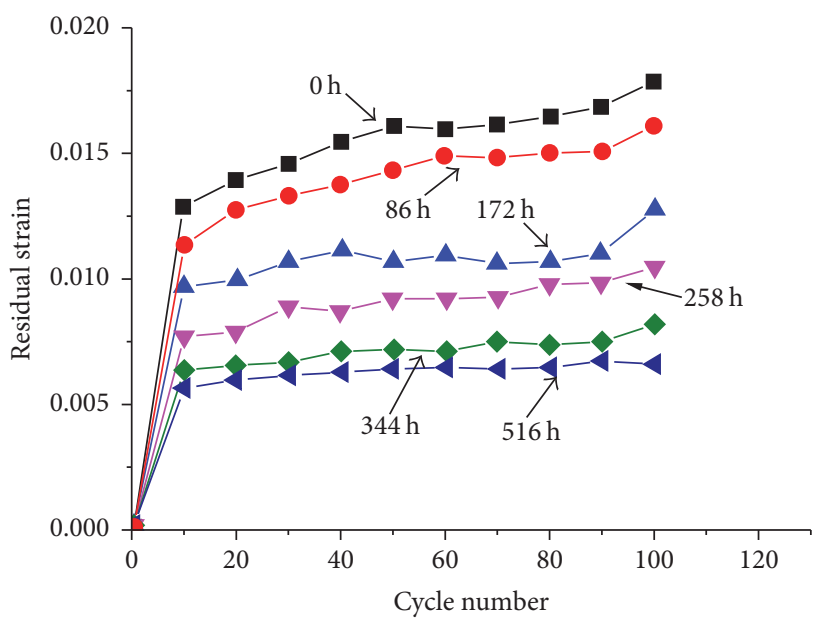

(b) Weft

FIGURE 5: Relationship between cycle number and residual strain after different aging times.

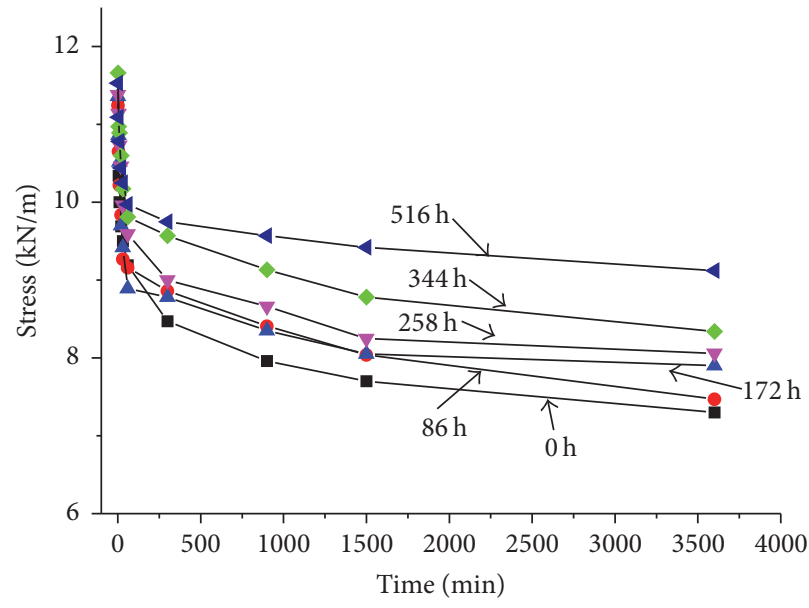

(a) Warp

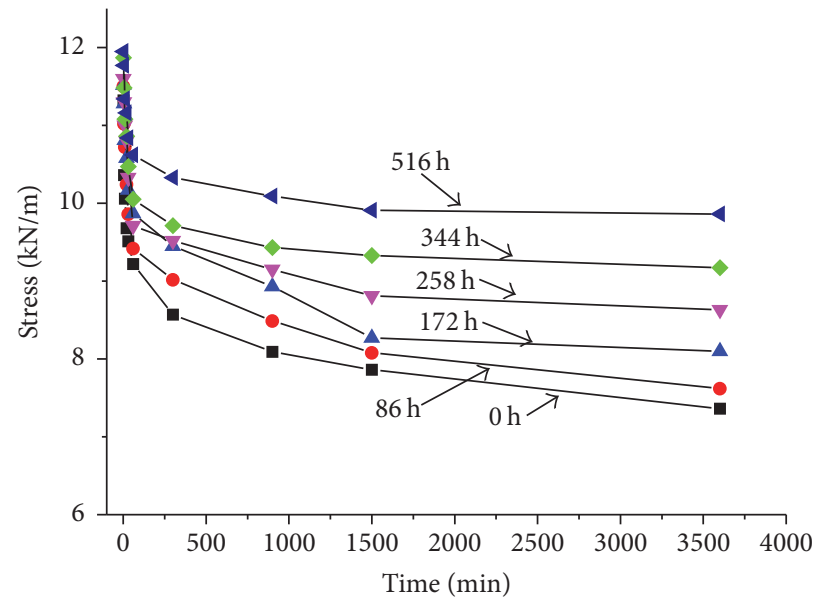

(b) Weft

FIgURE 6: Stress-relaxation behaviors after different aging times.

begin to peel and the deformation increases fast and the stress increases slowly. The secant slopes of aging materials after cyclic loading are higher than those without cyclic loading. In the third phase, the differences between them are more significant.

Figure 8 shows the materials after cyclic loading; with aging time increasing, the tensile strength decreases slightly, while the strain at break remained almost unchanged. The tensile strength of materials after cyclic loading is higher than those without cyclic loading. After 172 hours, the degradation ratio of material strength is $1.83 \%$ and $1.67 \%$ in warp and weft, respectively. For the aging materials after cyclic loading, the tensile strength increases and the strain at break decreases, compared with those without cyclic loading. It should be noticed that the tensile strength of materials after aging and cyclic loading is very close to the reference materials (the aging time of $0 \mathrm{~h}$ and without cyclic loading). This is maybe related to the material strength increasing slightly due to the material hardening after cyclic loading, while the degradation of yarn properties is not significant due to less aging time.

From the above, the cyclic loading can enhance the tensile stiffness (the secant slope of tensile curves) slightly, because it can decrease the crimps of the woven structures. When the aging time is short, the cyclic loading may increase the tensile strength due to material hardening induced by cyclic loading and the aging effect is not significant. However, if the aging time is longer, the tensile strength will decrease due to aging of yarns.

3.2.2. Stress Relaxation. The artificial accelerated aging tests are carried out on the materials after stress-relaxation tests. The tensile curves of aging materials after and without stress relaxations are shown in Figure 9. Figure 10 shows the tensile strength and strain at break of the materials under different conditions. After stress relaxation, the tensile strength and strain at break decrease significantly. The stress-relaxation 


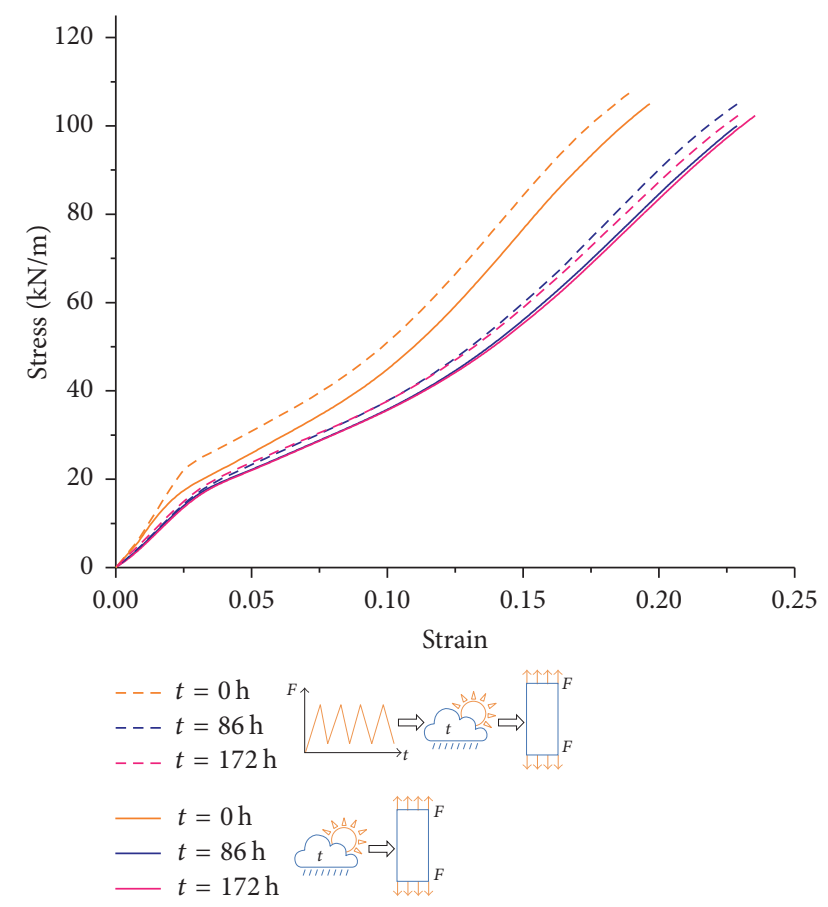

(a) Warp
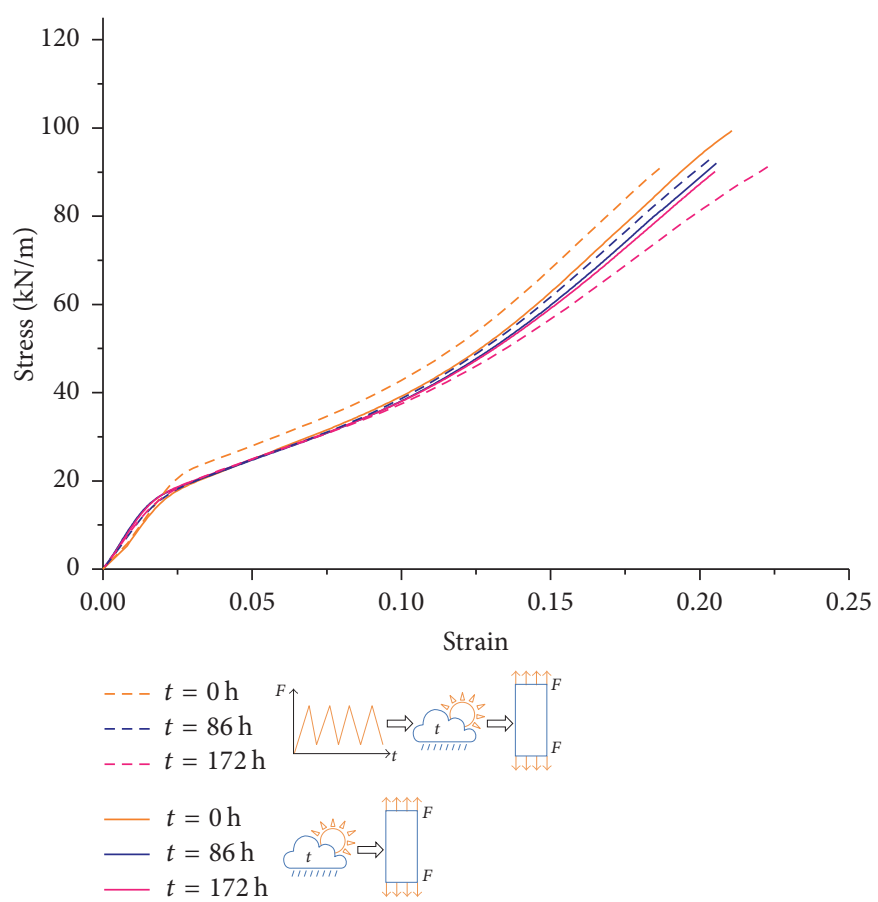

(b) Weft

FIGURE 7: Tensile curves of aging materials (with or without cyclic loading).

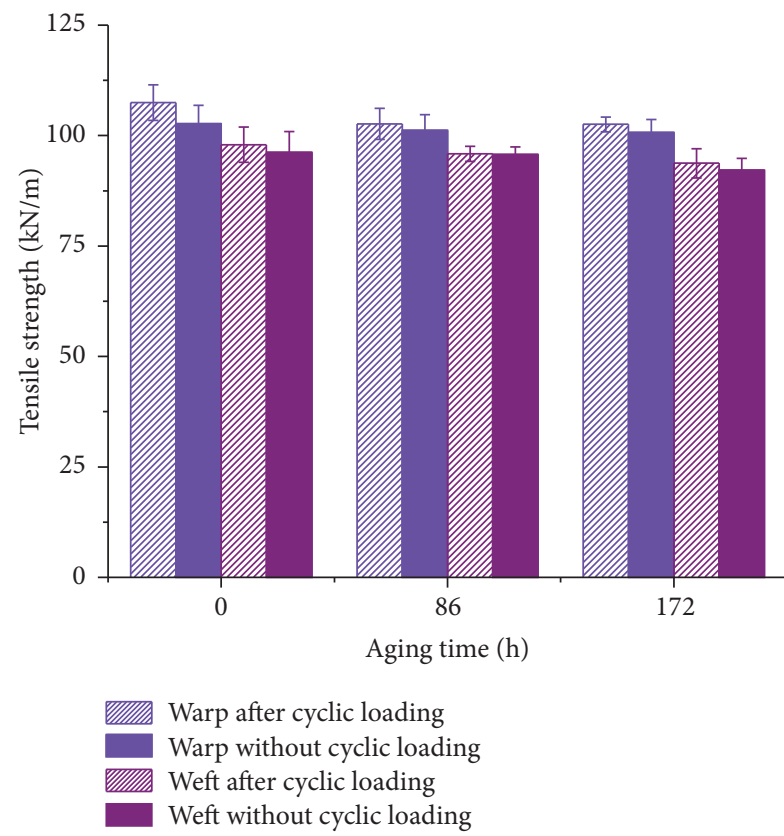

(a) Tensile strength

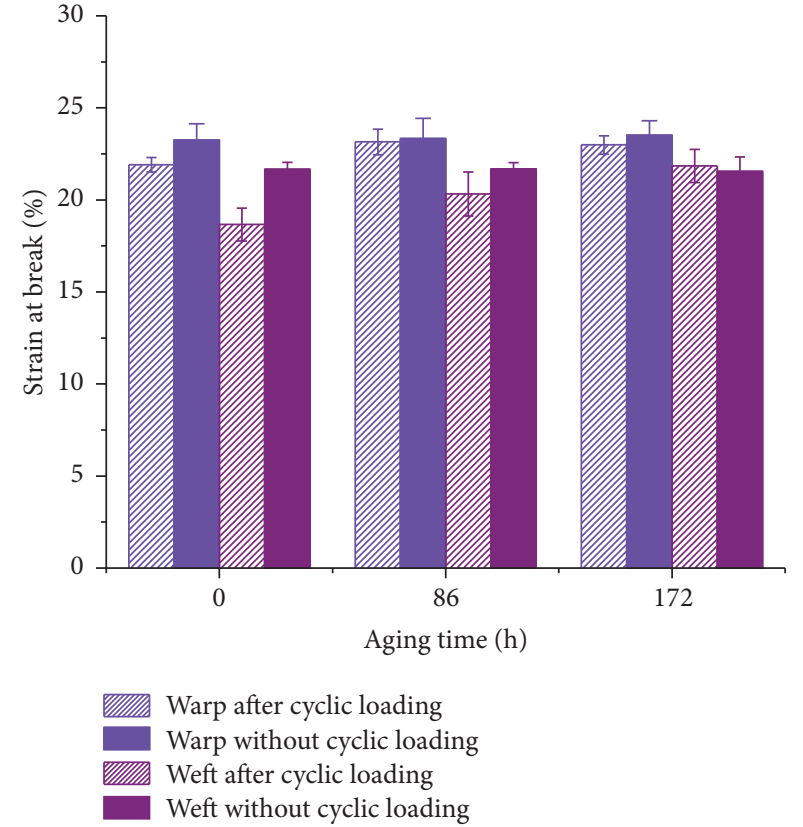

(b) Strain at break

FIGURE 8: Tensile properties of materials (after cyclic loading) after aging.

test can decrease the materials tensile stiffness, because it can change crimp degree of substrate and coating thickness. The following aging tests continue to decrease the tensile stiffness. The following aging tests can lead to the decrease of tensile properties. Compared with the materials after stress relaxations before aging, the tensile strength after 172 hours aging decreases about $11.74 \%$ and $7.89 \%$ in warp and weft, respectively. After both accelerated aging tests and stressrelaxation tests, the tensile strength and strain at break decrease significantly, compared with the reference materials. 


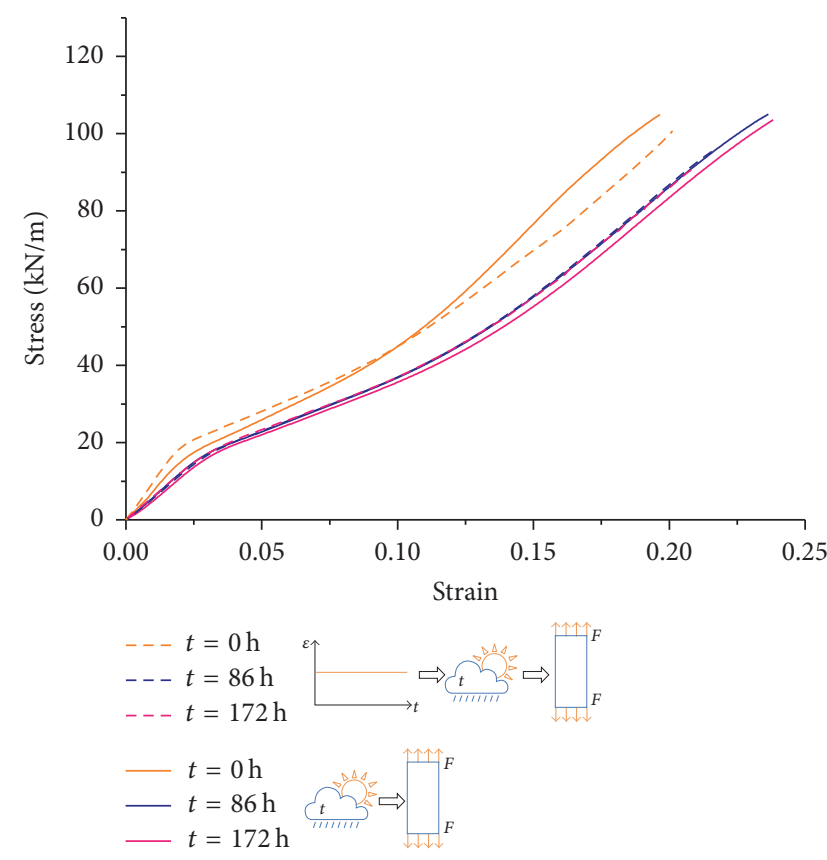

(a) Warp
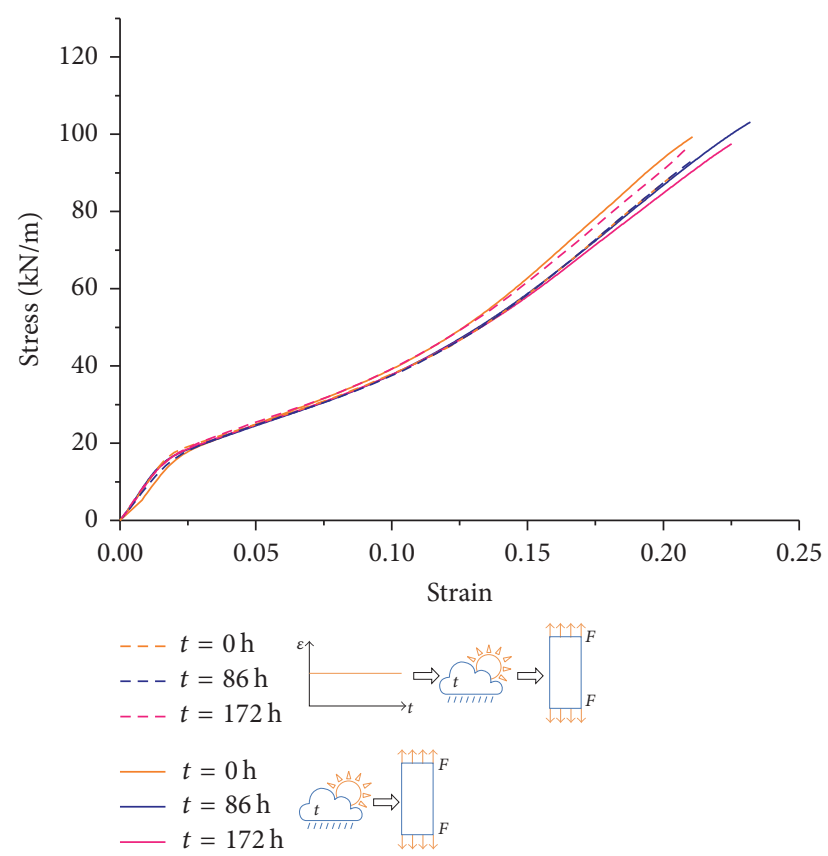

(b) Weft

FIgURE 9: Tensile curves of different materials (after or without relaxation) after aging.

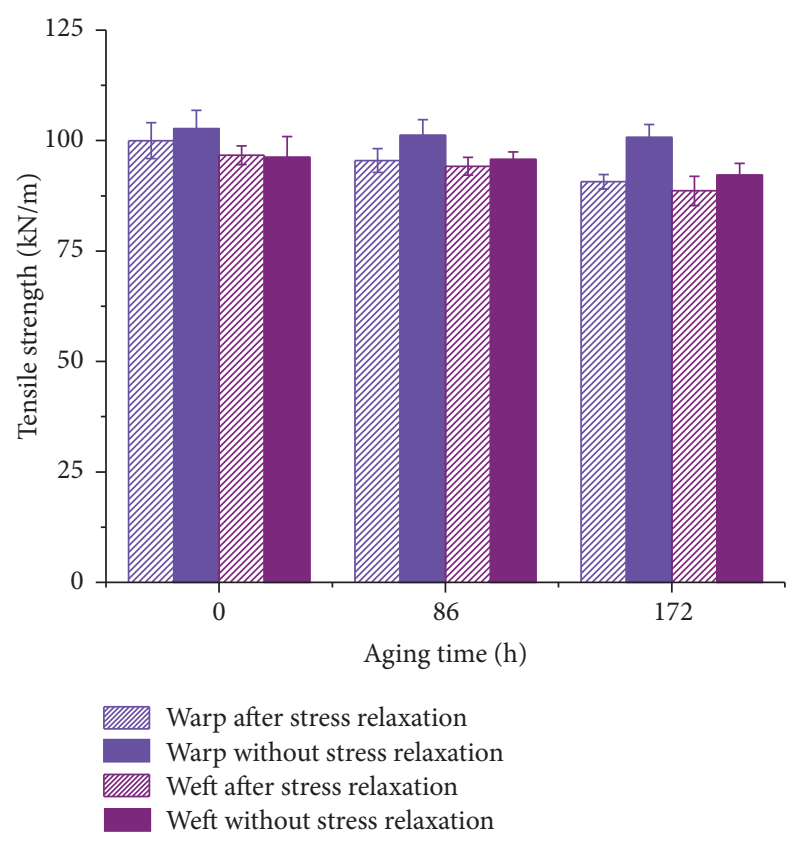

(a) Tensile strength
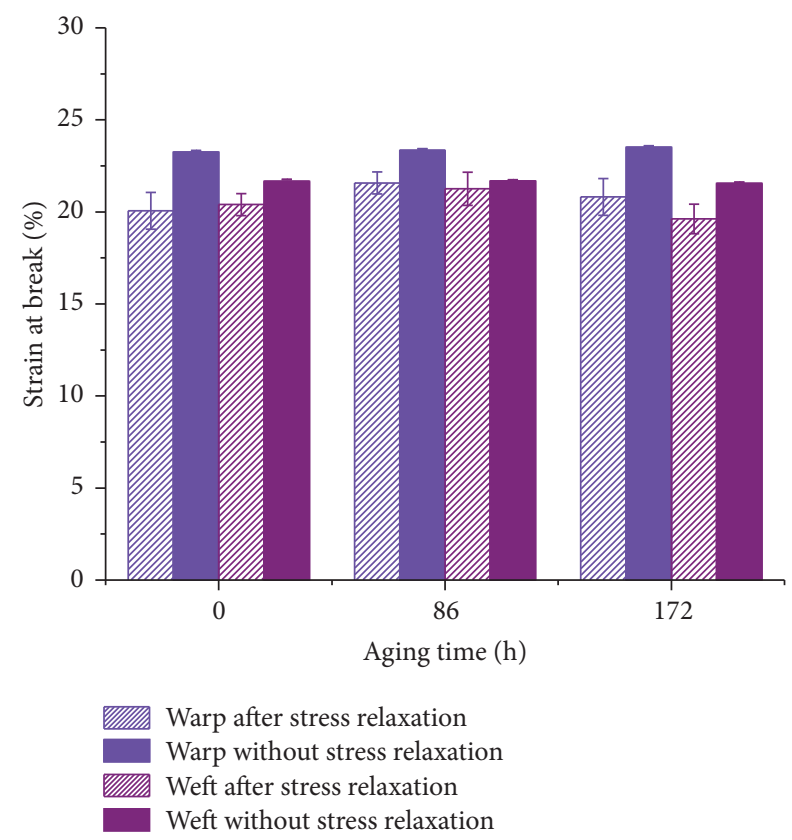

(b) Strain at break

FIGURE 10: Tensile properties of materials (after stress relaxation) after aging.

For the materials preloaded by stress-relaxation tests, the degradation ratio of tensile strength is higher than that of those preloaded by cyclic loading, $9.98 \%$ and $3.88 \%$ in warp and weft, respectively.

3.3. Summary. Actually, there are many similar aspects between cyclic loading and long-time sustained loading.
The long-term loading can decrease the crimps of woven structure significantly and increase the material stiffness with loading time or cycle number increasing. If the loading time is enough, significant decrease of material strength can be observed due to fatigue effects of yarn properties. Compared with the aging materials without preloading, the tensile strength of materials after cyclic loading increases and 
material hardening is observed. Thus, the initial stress in stress-relaxation tests is $12 \mathrm{kN} / \mathrm{m}$, which is close to the upper limit of stress amplitude in cyclic tests. Therefore, in stressrelaxation tests, the damage accumulations of load effects are relatively higher than that in the cyclic tests and more significant strength degradations can be observed.

However, because the stress-relaxation test always takes too long time, the cyclic tensile test may be a good choice to simulate the effect of loads. Here, a method composed of cyclic test and artificial accelerated test is proposed to study further the coupling effect of long-term loading and environment. First, the materials are tested by cyclic tensile tests with higher stress amplitude and the upper limit is no less than the design strength, about $1 / 4$ of uniaxial tensile strength. This step is to decrease the crimps in the microscopic structures and simulate the effects of loads. Second, the aging tests are carried out by the artificial accelerated tests. The aging time can be defined based on the acceleration ratio of aging equipment and the designed service life of membrane structures. Third, the residual properties of the materials are tested by uniaxial tensile tests and the corresponding mechanical parameters are obtained, including tensile strength, strain at break, elastic modulus, and adhesive strength. This method is similar to the determination of compensation ratio in the cutting pattern design of membrane structures [2]. In fact, the determination of compensation ratio is also based on the material properties under the effects of loads and environment. Further researches can be imposed on proposing an accurate relationship between loading effect and temperature. Therefore, it may be easier to obtain the mechanical behaviors of coated fabrics under the coupling effect of long-term loading and environment.

\section{Conclusions}

This paper studied the aging properties of PVDF-coated polyesters under the effects of loads and environments. From the appearance, the surfaces became yellow and darkened, while the stains and spots can also be observed. Significant aging phenomenon can be observed on the surface coating. The main mechanical parameters decrease with aging time increasing, including tensile strength, tear strength, and elastic modulus. The degradation ratio of elastic modulus is lower than that of tensile strength and tear strength. The ultraviolet radiation and the temperature mainly affect the mechanical properties of yarns. The decrease of tensile strength mainly depends on the aging degree of coating and yarns, which is related to the aging time. Besides, the strain at break is slightly affected by aging.

For the materials after precyclic loading and aging, the residual properties with cyclic loading are better than those without cyclic loading. However, for the materials after prestress relaxations and aging, the material properties decrease significantly compared with those without stress relaxations. This is because the initial stress in stress-relaxation tests is high and the damage accumulations of load effects are higher than that in the cyclic loading. The short-term loading mainly increases the tensile stiffness, because it mainly reduces some crimps due to the manufacture process. Meanwhile, the longterm loading can lead to the decrease of both tensile strength and tensile stiffness, due to long-term fatigue effects of yarns.

The degradation behaviors of membrane materials can be considered as the accumulation of various effects, including environment and loads. The method composed of cyclic tests with higher stress amplitude and artificial accelerated tests is suggested to study the long-term effect of loads and environment. This paper can be references for the quantitative analysis of mechanical properties of coated fabrics under the effects of environment and loads.

\section{Conflicts of Interest}

The authors declare that there are no conflicts of interest regarding the publication of this paper.

\section{Acknowledgments}

This work is supported by National Natural Science Foundation of China under Grant no. 51678563 and the Fundamental Research Funds for the Central Universities under Grant no. 2015XKMS012. The authors thank Professor Qilin Zhang for his help with the test machine.

\section{References}

[1] Y. Li, Study and Applications on Mechanical Properties of Membrane Materials and Structures, Tongji University, Shanghai, China, 2007.

[2] B. Forster and M. Mollaert, "European Design Guide for Tensile Surface Structures,” Tensinet, 2004.

[3] Y. Y. Zhang, Q. L. Zhang, C. Z. Zhou, and Y. Zhou, "Mechanical properties of PTFE coated fabrics," Journal of Reinforced Plastics and Composites, vol. 29, no. 24, pp. 3624-3630, 2010.

[4] B. N. Bridgens and M. J. S. Birchall, "Form and function: The significance of material properties in the design of tensile fabric structures," Engineering Structure, vol. 44, pp. 1-12, 2012.

[5] P. D. Gosling, B. D. Bridgens, and L. Zhang, "Adoption of a reliability approach for membrane structure analysis," Structural Safety, vol. 40, pp. 39-50, 2013.

[6] B. L. Kuai, Weathering Properties of PVC Coated Membrane Material, Tongji University, Shanghai, China, 2013.

[7] X. D. Yang and X. Ding, "Progress of Study on the aging of PVC-coated membrane material," Synthetic Materials Aging and Application, vol. 41, no. 2, pp. 44-54, 2012.

[8] R. Sallis, "High performance coated fafbric structural materials," Journal of Industrial Textiles, vol. 14, no. 1, pp. 36-45, 1984.

[9] M. P. Ansell, C. A. S. Hill, and C. Allgood, "Architectural PTFEcoated glass fabrics-their structure and limitations," Textile Research Journal, vol. 53, no. 11, pp. 692-700, 1983.

[10] W. F. Polfus, "Weathering of industrial fabrics (accelerated and natural)," Journal of Industrial Textiles, vol. 7, no. 1, pp. 58-62, 1977.

[11] U. Eichert, "Residual tensile and tear strength of coated industrial fabrics determined in long-time tests in natural weather conditions," Journal of Industrial Textiles, vol. 23, no. 4, pp. 311327, 1994. 
[12] H. Toyada, S. Nireky, H. Jutunen, and T. Ohnuma, "Durability of PVC Coated Fabric for Membrane Structures," I.A.S.S.S, 1990, Dresden and Cottbus.

[13] H. Toyada, H. Sakabe, T. Itoh, T. Konishi, and T. Torii, "Weatherability of Membrane Structure Materials as Determined by Exposure Conditions," ESN 1 Gakkaishi, 1994.

[14] R. Levinson, P. Berdahl, A. A. Asefaw Berhe, and H. Akbari, "Effects of soiling and cleaning on the reflectance and solar heat gain of a light-colored roofing membrane," Atmospheric Environment, vol. 39, no. 40, pp. 7807-7824, 2005.

[15] H. A. Razak, C. S. Chua, and H. Toyoda, "Weatherability of coated fabrics as roofing material in tropical environment," Building and Environment, vol. 39, no. 1, pp. 87-92, 2004.

[16] K. Zerdzicki, P. Kłosowski, and K. Woznica, "Application of the Bodner-Partom constitutive equations for modelling the technical fabric Valmex used for the hanging roof of the Forest Opera in Sopot," in Shell Structures: Theory and Applications, W. Pietraszkiewicz and J. Gorski, Eds., vol. 3, pp. 579-82, Taylor; Francis/Balkema, London, UK, 2014.

[17] M. P. Ansell, "The degradative effect of boiling water on polyester fibres in a PVC-coated fabric," Journal of Industrial Textiles, vol. 14, no. 4, pp. 242-255, 1985.

[18] P. Mailler, G. Nemoz, and P. Hamelin, "Long Term Behavior Characterization of Coated Fabrics for Architecture Membrane under Biaxial Loading," Journal of Industrial Textiles, vol. 27, pp. 323-333, 1997.

[19] H. F. Liu, J. Han, and Z. Y. Zou, "Study on the tensile properties of membrane structure material in ultraviolet radiation," Journal of Zhejiang Science-Technology University, vol. 27, no. 1, pp. 26-30, 2009.

[20] W. C. Qiu, X. D. Yang, X. Ding, and C. Hu, "hoto-oxidation of PVC-coated membrane material," Journal of Textile Researh, vol. 31, no. 12, pp. 33-38, 2010.

[21] W. J. Martin, W. J. Chin, and T. Nguyen, "Reciprocity law experiments in polymeric photo degradation: a critical review," Progress in Organic Coatings, vol. 47, no. 3-4, pp. 292-311, 2003.

[22] J. Chin, N. T. Nguyen, D. Byrd, and J. Martin, "Validation of the reciprocity law for coating photodegradation," Journal of Coatings Technology and Research, vol. 2, no. 7, pp. 499-508, 2005.

[23] Z. L. Tan, "Estimation of the aging resistance of membrane structure materials under thermal, humid and ultraviolet conditions," Journal of Applied Polymer Science, 2008, Shanghai, China, Donghua University.

[24] F. J. Wang, Study on the Photo-Oxidation of PVC-Coated Membrane Material under Tensile Stresses, Donghua University, Shanghai, China, 2015.

[25] A. K. Sen, Coated Textiles: Principles and Applications, CRC Press, 2nd edition, 2007.

[26] Y. Y. Zhang, Q. L. Zhang, B. L. Kuai, and K. Lei, "Experimental analysis of tensile behaviors of polytetrafluoroethylene-coated fabrics subjected to monotonous and cyclic loading," Textile Research Journal, vol. 84, no. 3, pp. 231-245, 2014.

[27] Serge Ferrari Company, http://en.sergeferrari.com/corporate-en/ precontraint-serge-ferrari-patented-technology/.

[28] Y. Y. Zhang, Q. L. Zhang, and H. L. Lv, "Mechanical properties of PVC coated fabrics processed with precontraint ${ }^{@}$ technology," Journal of Reinforced Plastics and Composites, vol. 31, no. 23, pp. 1670-1684, 2012.

[29] A. Ambroziak, "Mechanical properties of Precontraint 1202S coated fabric under biaxial tensile test with different load ratios," Construction and Building Materials, vol. 80, no. 1, pp. 210-224, 2015.
[30] A. Ambroziak, "Mechanical properties of polyester coated fabric subjected to biaxial loading," Journal of Materials in Civil Engineering, vol. 27, no. 11, Article ID 04015012, 2015.

[31] International Organization for Standardization. ISO 48922:2013, Plastics-Methods of exposure to laboratory light sourcesPart 2: Xenon-arc lamps, 2013.

[32] DG/TJ08-2019-2007, "Inspection guidelines for membrane structures," Shanghai, China.

[33] J. W. Chen and W. J. Chen, "Central Crack Tearing Testing of Laminated Fabric Uretek3216LV under Uniaxial and Biaxial Static Tensile Loads," Journal of Materials in Civil Engineering, vol. 28, no. 7, Article ID 04016028, 2016.

[34] H. L. Yi, X. Ding, and S. H. Chen, "Estimation of the elastic constants of architectural membrane under biaxial tensile loading," Engineering Mechanics, vol. 23, no. 10, pp. 180-183, 2006.

[35] J. W. Chen, W. J. Chen, and D. X. Zhang, "Experimental study on uniaxial and biaxial tensile properties of coated fabric for airship envelopes," Journal of Reinforced Plastics and Composites, vol. 33, no. 7, pp. 627-644, 2014.

[36] Z. R. Chen, B. L. Kuai, and Q. L. Zhang, "Experimental research on mechanical properties of PVC membrane after artificial accelerated aging," Structural Engineer, vol. 32, no. 4, pp. 119124, 2013.

[37] Z. R. Chen, Q. L. Zhang, and W. L. Xue, "Experimental research on mechanical properties of PVC membrane after aging," IASS Symposium, 2013.

[38] Y. Y. Zhang, X. G. Song, Q. L. Zhang, and H. L. Lv, "Fracture failure analysis and strength criterion for PTFE-coated woven fabrics," Journal of Composite Materials, vol. 49, no. 12, pp. 14091421, 2015. 

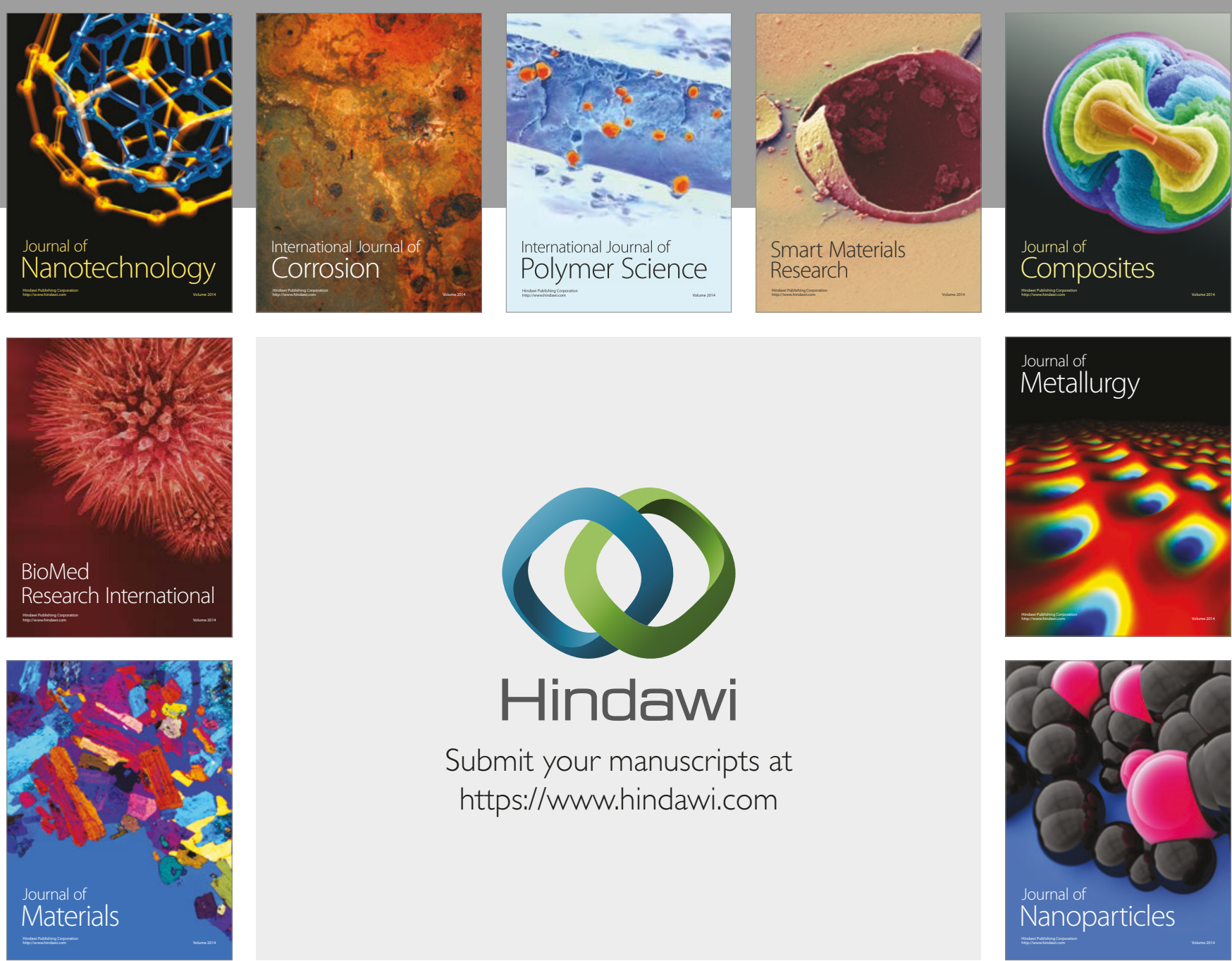

\section{Hindawi}

Submit your manuscripts at

https://www.hindawi.com
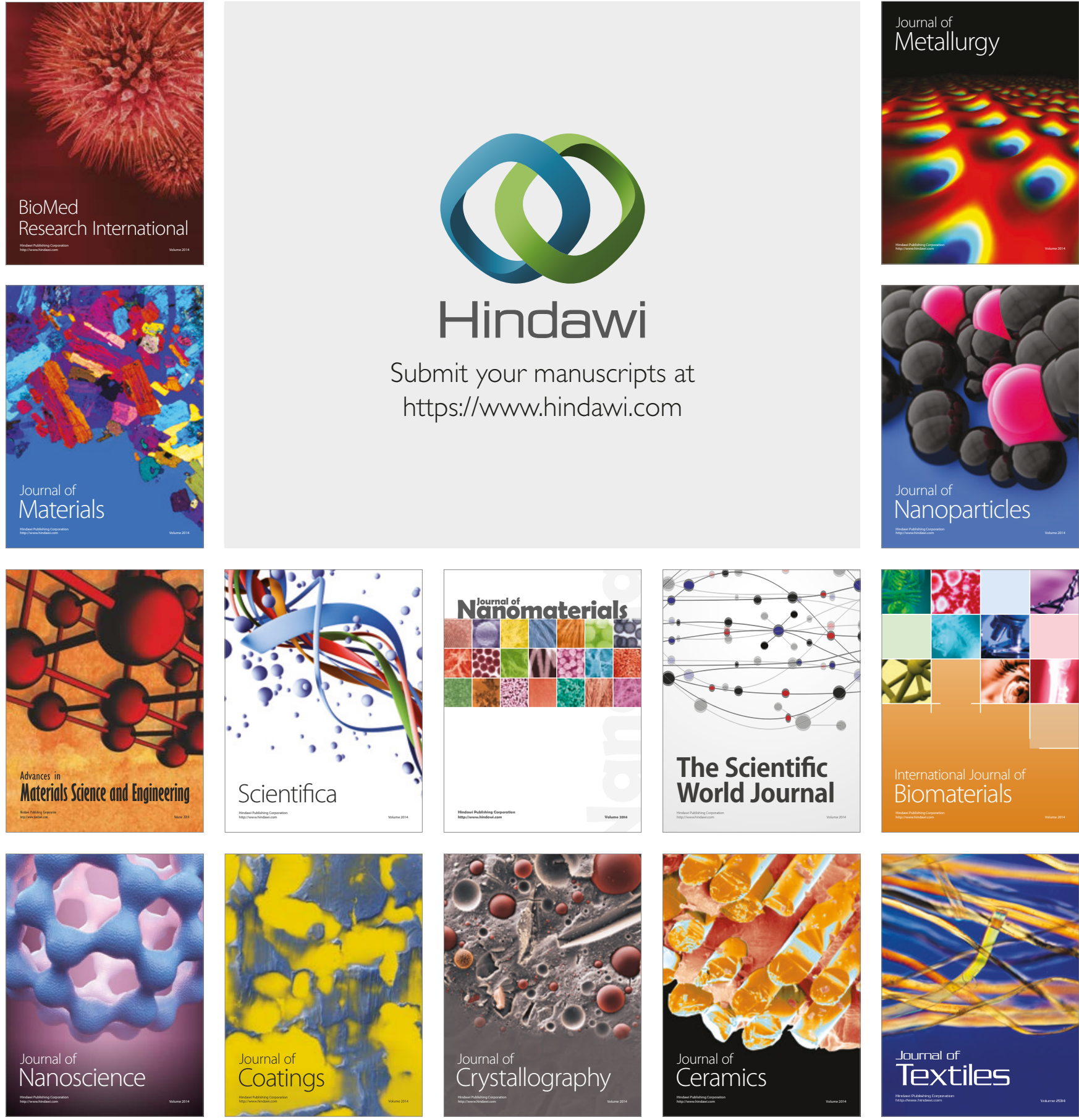

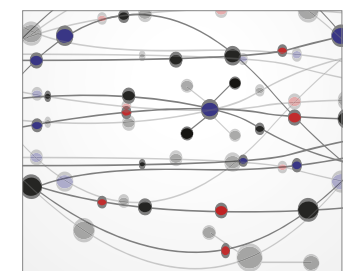

The Scientific World Journal
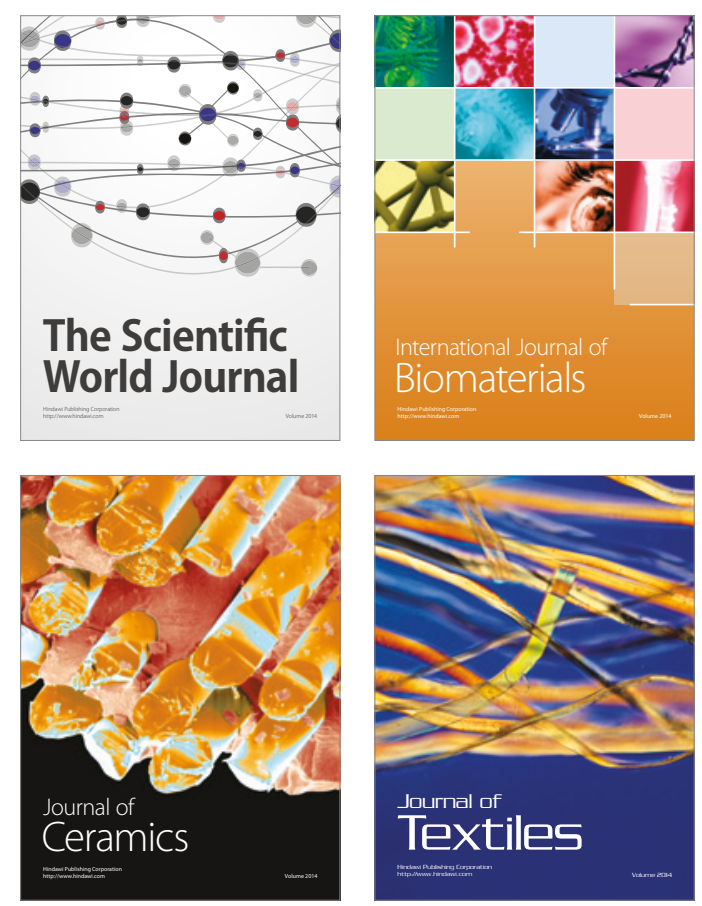